(C) [2009] IEEE. Reprinted, with permission, from [Yongchang Zhang, Zhengming Zhao, Jianguo Zhu, Wei Xu and D. G. Dorrell, Speed sensorless direct torque control of 3-level inverter-fed induction motor drive based on optimized switching table, Industrial Electronics, 2009. IECON '09. 35th Annual Conference of IEEE, 3-5 Nov. 2009]. This material is posted here with permission of the IEEE. Such ermission of the IEEE does not in any way imply IEEE endorsement of any of the University of Technology, Sydney's products or services. Internal or personal use of this material is permitted. However, permission to reprint/republish this material for advertising or promotional purposes or for creating new collective works for resale or redistribution must be obtained from the IEEE by writing to pubspermissions@ieee.org. By choosing to view this document, you agree to all provisions of the copyright laws protecting it 


\title{
Speed Sensorless Direct Torque Control of 3-Level Inverter-Fed Induction Motor Drive Based on Optimized Switching Table
}

\author{
Yongchang Zhang $^{1^{*}}$, Zhengming Zhao ${ }^{2}$, Jianguo $\mathrm{Zhu}^{1}$, Wei Xu ${ }^{1}$, D. G. Dorrell ${ }^{1}$ \\ ${ }^{1}$ School of Electrical, Mechanical and Mechatronics Systems, University of Technology Sydney, NSW2007, Australia \\ ${ }^{2}$ State Key Laboratory of Power System, Department of Electrical Engineering, Tsinghua University, China \\ zhangdavid37@gmail.com
}

\begin{abstract}
Three-level neutral-point-clamped (NPC) inverters are very appropriate for high-power adjustable-speed drive applications. Direct torque control is characterized by the merits of fast response, simple structure and strong robustness to motor parameters variations. This paper presents a 3-level inverter-fed direct torque controlled (DTC) induction motor (IM) drive based on optimized switching table. The problems of high voltage jump, smooth vector switching and neutral point balance are investigated and solved by introducing appropriate intermediate vectors. Furthermore, a speed-adaptive flux observer is employed to enhance the performance of the system by estimating the state variables including the stator flux and state current. Large starting current, which can occur in conventional DTC drives, is controlled effectively by introducing pre-excitation of the stator flux. Both simulation and experimental results are presented to verify the effectiveness of the proposed schemes introduced in this paper.
\end{abstract}

\section{INTRODUCTION}

Three-level inverters have become widespread in highpower industrial applications since they were first proposed by Nabae in 1981 [1]. Compared to 2-level inverters, they have better performance in terms of lower voltage stress across the semiconductors, less harmonic content and lower switching frequency [2]. Direct torque control (DTC) is a kind of high performance control strategy characterized by fast torque response, simple structure (without complicated rotary transformation) and strong robustness against motor parameter variation. Three-level inverter-fed DTC motor drives are very attractive in high power applications because they combine the merits of both 3-level inverters and DTC.

Most papers [3-4] related to DTC concentrate on 2-level inverters; there are few papers related to 3-level DTC [5]. To make 3-level DTC practicable, an appropriate vector should be selected to maintain the neutral point voltage balance and avoid high voltage jump. The principles of a commercial 3level DTC adjustable speed drive (ASD), as manufactured by $\mathrm{ABB}$, was introduced in [6]; however, there were undesirable high voltage jumps in the line voltage. To reduce the oscillation in the flux and torque, a LC filter was employed which increases the complexity of flux observation. Ref [5] improves the low speed performance of the 3-level DTC by applying the correct intermediate voltage; however, the problems of voltage jump and neutral point balance were not addressed.
This paper focuses on the problems of voltage jump and neutral point balance by incorporating an optimized switching table. To improve the low speed performance, a speedadaptive flux observer is employed to estimate the stator flux, electromagnetic torque and rotor speed over a wide speed range. There is usually large starting current in conventional DTC [7] schemes and this paper solves this problem by introducing the pre-excitation of stator flux. The proposed schemes are simulated and experimentally verified.

\section{DTC FOR 3-LEVEL INVERTER}

\section{A. Basic Principle of DTC}

The mathematical model of an induction motor described by space vectors in a stationary frame by the following set of equations:

$$
\begin{aligned}
& \boldsymbol{u}_{s}=R_{s} \boldsymbol{i}_{s}+p \boldsymbol{\psi}_{s} \\
& 0=R_{r} \boldsymbol{i}_{r}+p \boldsymbol{\psi}_{r}-j \omega_{r} \boldsymbol{\psi}_{r} \\
& \boldsymbol{\psi}_{s}=L_{s} \boldsymbol{i}_{r}+L_{m} \boldsymbol{i}_{r} \\
& \boldsymbol{\psi}_{r}=L_{m} \boldsymbol{i}_{s}+L_{r} \boldsymbol{i}_{r}
\end{aligned}
$$

where us, $\boldsymbol{i}_{\boldsymbol{s}}, \boldsymbol{i}_{r}, \boldsymbol{\psi}_{\boldsymbol{s}}$ and $\boldsymbol{\psi}_{r}$ are the stator voltage vector, stator current vector, rotor current vector, stator flux linkage vector and rotor flux linkage vector, respectively; $R_{s}, R_{r}, L_{s}, L_{r}, L_{m}$ and $N_{p}$ are the stator resistance, rotor resistance, stator inductance, rotor inductance, mutual inductance and motor pole-pair number; $\omega_{r}$ is the rotor speed.

From the stator voltage equation (1), it can be seen that, by omitting the stator resistance voltage drop, the stator flux can be controlled directly from the stator voltage. This is a crude analysis and may cause error at low speed.

The electromagnetic torque can be expressed as

$$
T_{\mathrm{e}}=\frac{3}{2} N_{p} \frac{L_{m}}{\sigma L_{s} L_{r}} \psi_{r} \otimes \psi_{s}=\frac{3}{2} N_{p} \frac{L_{m}}{\sigma L_{s} L_{r}}\left\|\psi_{r}\right\| \cdot\left\|\psi_{s}\right\| \cdot \sin \delta_{s r}
$$

where $\delta_{s r}$ is the spatial angle between stator flux and rotor flux and $T_{e}$ is the electromagnetic torque. In the DTC, the amplitude of the stator flux is kept constant and a fast torque response is obtained by changing angle $\delta_{s r}$ quickly. From (1)(4), the relationship between the stator flux and the rotor flux can be obtained from 
$p \psi_{r}+\left(\frac{1}{\sigma T_{r}}-j \omega_{r}\right) \psi_{r}=\frac{L_{m}}{\sigma L_{s} T_{r}} \psi_{s}$

where $\sigma=1-L_{\mathrm{m}}^{2} /\left(L_{\mathrm{s}} L_{\mathrm{r}}\right)$ and $T_{\mathrm{r}}=L_{\mathrm{r}} / R_{\mathrm{r}}$. Eqn. (6) indicates that the dynamic response of the rotor flux is a first-order lag with respect to the stator flux, so the torque can be changed quickly by changing the angle of stator flux.

\section{B. Vector Selection and Switching}

For a 2-level DTC, the sector division and vector selection methods are relatively mature. However, for a 3-level DTC, because of the increased number of vectors, vector selection is more complicated, and in this paper we will solve the problem step by step.

Firstly, the vector is selected according to the demand of flux and torque; vector switching and neutral point balance will be considered later. Fig. 1 shows the space vector diagram for a 3-level DTC control strategy and its sector division. There are 12 sectors and the shadowed area is the first vector, which is different from that of the conventional 2-level DTC. The basic principles of the vector selection are shown in Table I and these meet the demands of the flux and torque; $\mathrm{k}$ represents the stator flux located in $\mathrm{k}^{\text {th }}$ sector. In addition, "^" means increase while " $\downarrow$ " means decrease, and "=" means no change is needed. It should be noted that more than two vectors may exist to meet the demands of the flux, and a vector which meets the torque response better is preferred.

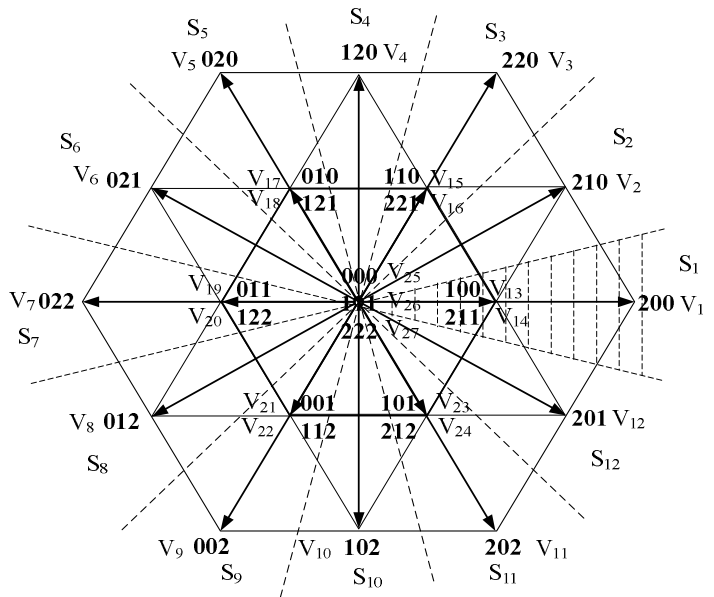

Fig. 1. Space vector diagram for the 3-level DTC.

However, in most cases, the selected vector usually cannot meet the requirements of the vector switching and neutral point balance, which means the selected vector cannot be applied to the 3-level inverter directly. For example, suppose the stator flux is located in the first sector, and the current vector is $V_{1}$ (200). To increase the stator flux and torque, according to Table $\mathrm{I}, \mathrm{V}_{3}$ (220) would be the appropriate vector. But there is a high voltage jump in phase B from 0 to 2, which should be avoided. In this case, $V_{2}$ (210) will be inserted as an intermediate vector to smooth the high voltage jump. There are three aspects to voltage jumps: 1) phase voltage jump, 2) line voltage jump, 3) 3-phase jump at the same time. High voltage jump increases harmonic content and the stress across power semiconductors, which negates the advantages of the 3-level inverter. To overcome this problem, an appropriate intermediate vector should be inserted to meet the requirement of the voltage jump.

TABLE I

OPTIMIZED TABLE FOR 3-LEVEL DTC

\begin{tabular}{|c|c|c|}
\hline Flux & Torque & Selected vector number \\
\hline \multirow{3}{*}{$\uparrow$} & $\uparrow$ & $\mathrm{k}+2$ \\
\hline & $\downarrow$ & 26 \\
\hline & $=$ & $\mathrm{k}-2$ \\
\hline \multirow{3}{*}{$\downarrow$} & $\uparrow$ & $\mathrm{k}+4$ \\
\hline & $\downarrow$ & 26 \\
\hline & $=$ & $\mathrm{k}-4$ \\
\hline \multirow{3}{*}{$=$} & $\uparrow$ & $\mathrm{k}+3$ \\
\hline & $\downarrow$ & 26 \\
\hline & $=$ & $\mathrm{k}-3$ \\
\hline
\end{tabular}

Another issue is the problem of neutral point balance, which is very important for a 3-level inverter, because neutral point unbalance will cause higher voltage in the power semiconductors. This increases the demand of capacity so that the cost increases. Many papers have investigated this problem. Neutral point balance is mainly controlled by selecting appropriate small vectors; this is because of the opposite effects of redundant vectors. In this paper, we also adopt the redundant states of small vector to keep neutral point balance.

The final vector selection rules are obtained by considering the aspects introduced above, and the principles are summarized as follows:

Step I: select vector according to the demands for flux and torque, which are listed in Table I;

Step II: if the selected vector cannot meet the requirement of voltage jump and neutral point balance, an appropriate intermediate vector will inserted, and principles for selecting the intermediate vector are:

1) Large vectors or middle vectors should be selected preferably to increase the utilization ratio of DC bus;

2) Middle vectors can switch to adjacent small vectors and large vectors freely;

3) Large vectors can switch to the small vectors in the same spatial orientation;

4) Small vectors can switch to zero vectors freely;

5) When small vectors are available, select the one which can meet the requirement of neutral point balance.

Using to the steps above, an appropriate vector can be selected to meet the demand of flux and torque, as well as the requirement of voltage jump and neutral point balance, which ensures the safe operation of the 3-level inverter.

\section{Decreasing Starting Current}

To decrease starting current and maintain sufficient starting torque, the scheme of pre-excitation of stator flux is proposed 
in this paper. The stator flux will firstly be established by applying an appropriate vector, and during the pre-excitation process, the starting current is sampled and when it reaches the limit, zero vectors will be selected to decrease the current, which acts in a bang-bang fashion. When stator flux enters the range of demand, the process of pre-excitation is terminated and motor can start with sufficient torque, because there is enough flux to produce torque.

\section{SPEED AdAPTIVE FluX OBSERVER}

This paper adopts a novel speed adaptive flux observer with load torque observation and novel gains [8]. The mathematical model of observer is express as

$$
\begin{aligned}
p \hat{\boldsymbol{i}}_{s} & =-\left[\left(\frac{1}{\sigma T_{s}}+\frac{1}{\sigma T_{r}}\right)-j \omega_{r}\right] \hat{\boldsymbol{i}}_{s} \\
& +\frac{1}{\sigma L_{s}}\left(\frac{1}{T_{r}}-j \omega_{r}\right) \hat{\boldsymbol{\psi}}_{s}+\frac{1}{\sigma L_{s}} \boldsymbol{u}_{s}+G_{1}\left(\boldsymbol{i}_{s}-\hat{\boldsymbol{i}}_{s}\right) \\
p \hat{\boldsymbol{\psi}}_{s} & =-R_{s} \hat{\boldsymbol{i}}_{s}+\boldsymbol{u}_{s}+G_{2}\left(\boldsymbol{i}_{s}-\hat{\boldsymbol{i}}_{s}\right) \\
\frac{d \hat{\boldsymbol{\omega}}_{\mathrm{r}}}{d t} & =\frac{N_{\mathrm{p}}}{J}\left(\hat{T}_{\mathrm{e}}-\hat{T}_{\mathrm{L}}\right)+K_{\omega}\left[\Delta \boldsymbol{i}_{\mathrm{s}} \otimes\left(\lambda L_{\mathrm{r}} \hat{\boldsymbol{\psi}}_{\mathrm{s}}-\hat{\boldsymbol{i}}_{\mathrm{s}}\right)\right] \\
\frac{d \hat{T}_{L}}{d t} & =-K_{T}\left[\Delta \boldsymbol{i}_{s} \otimes\left(\lambda L_{\mathrm{r}} \hat{\boldsymbol{\psi}}_{\mathrm{s}}-\hat{\boldsymbol{i}}_{\mathrm{s}}\right)\right]
\end{aligned}
$$

where $\hat{\boldsymbol{i}}_{\mathrm{s}}$ and $\hat{\boldsymbol{\psi}}_{\mathrm{s}}$ are estimated stator current, estimated stator flux, respectively. $G_{1}=-\left(g_{1 \mathrm{r}}+j g_{1 \mathrm{i}}\right)$ and $G_{2}=-\left(g_{2 \mathrm{r}}+j g_{2 \mathrm{i}}\right)$ are the observer gains. $K_{\omega}$ and $K_{T}$ are positive constant gains. This paper employs a novel observer gain [1] to improve the stability of observer and it is expressed as

$$
\begin{aligned}
& g_{1 \mathrm{r}}=2 b \\
& g_{1 \mathrm{i}}=0 \\
& g_{2 \mathrm{r}}=b /\left(\lambda L_{\mathrm{r}}\right) \\
& g_{2 \mathrm{i}}=0
\end{aligned}
$$

where $b$ is a negative constant gain.

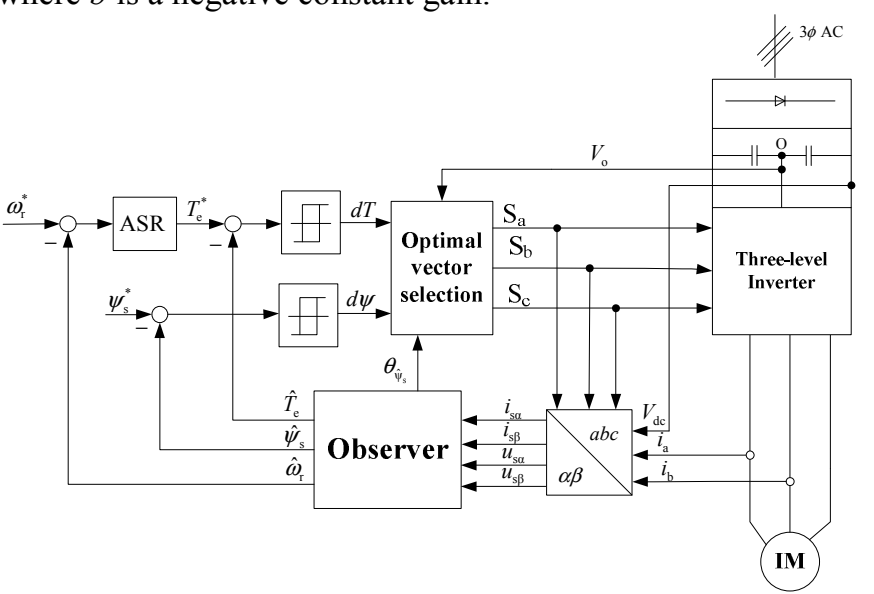

Fig. 2. Sensorless 3-level DTC drive.

\section{SIMULATION AND EXPERIMENTAL RESULTS}

To validate the effectiveness of the proposed techniques introduced in this paper, a system is simulated then validated experimentally, and the results are presented here. Fig. 2 illustrates the arrangement of the sensorless 3-level DTC drive implemented. The parameters for the simulation and experiments are listed in Table II.

TABLE II

SIMULATION AND EXPERIMENT PARAMETERS

\begin{tabular}{|l|c|c|}
\hline DC-bus voltage [V] & $V_{\mathrm{dc}}$ & 560 \\
\hline Rated motor power [kW] & $P_{N}$ & 2.2 \\
\hline Rated motor voltage [V] & $U_{N}$ & 380 \\
\hline Rated (Based) motor frequency [Hz] & $f_{N}$ & 50 \\
\hline Number of motor pairs & $N_{p}$ & 2 \\
\hline Motor stator resistance $[\Omega]$ & $R_{s}$ & 2.845 \\
\hline Motor rotor resistance [ $\Omega]$ & $R_{r}$ & 2.413 \\
\hline Motor mutual inductance $[\mathrm{H}]$ & $L_{m}$ & 0.2687 \\
\hline Motor stator inductance $[\mathrm{H}]$ & $L_{s}$ & 0.2815 \\
\hline Motor rotor inductance $[\mathrm{H}]$ & $L_{r}$ & 0.2815 \\
\hline
\end{tabular}

\section{A. Simulation Results}

Figs. 3 to 6 show the response of the 3-level sensorless induction motor drive, starting from $0 \mathrm{rpm}$ and going up to $1500 \mathrm{rpm}$ when unloaded. The stator flux is first established before $\mathrm{t}=0.05 \mathrm{~s}$ by using the pre-excitation technique, which can be seen from the upper half in Fig. 3. Then the motor accelerates up to $1500 \mathrm{rpm}$ with the permitted maximum torque. At about $\mathrm{t}=0.18 \mathrm{~s}$, the motor reaches the steady-state speed at $1500 \mathrm{rpm}$. A step load of 0.5 p.u. at $t=0.5 \mathrm{~s}$ is applied to test the robustness of DTC to an external disturbance. It can be seen in Fig. 4 that there is only a slight fall in speed and it returns to normal state quickly. This validates the excellent dynamic performance of the DTC. Fig. 5 gives the line voltage and voltage fluctuations at the neutral point while Fig. 6 shows the zoomed line voltage at 1500rpm. The neutral point voltage is controlled well and the oscillation is kept to within the range of $\pm 5 \mathrm{~V}$. There is no high voltage jump in either the line voltage or phase voltage, which validates the effectiveness of the proposed optimal vector table and the principle of the vector selection procedure.
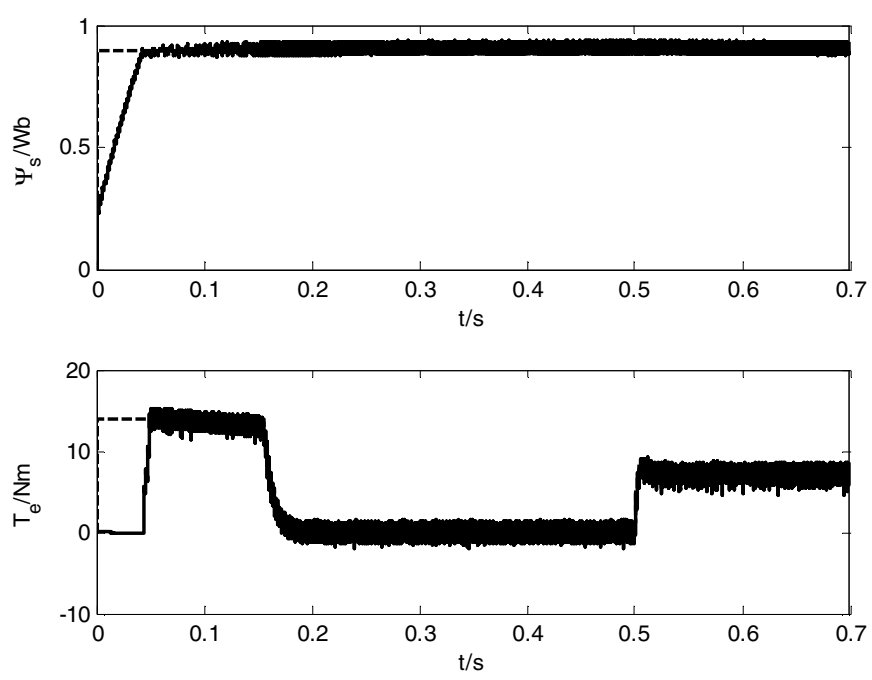

Fig. 3. Response of stator flux and torque. 

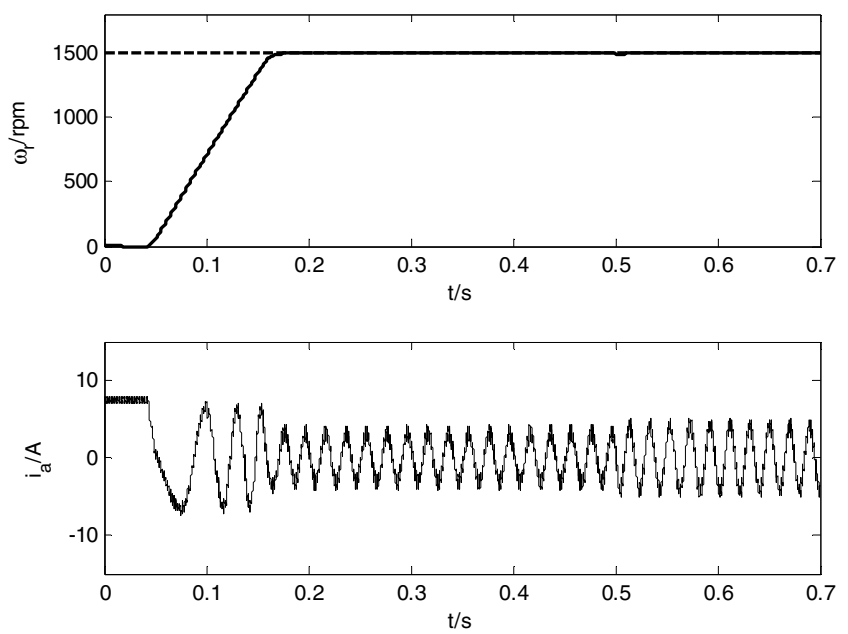

Fig. 4. Response of rotor speed and stator current.
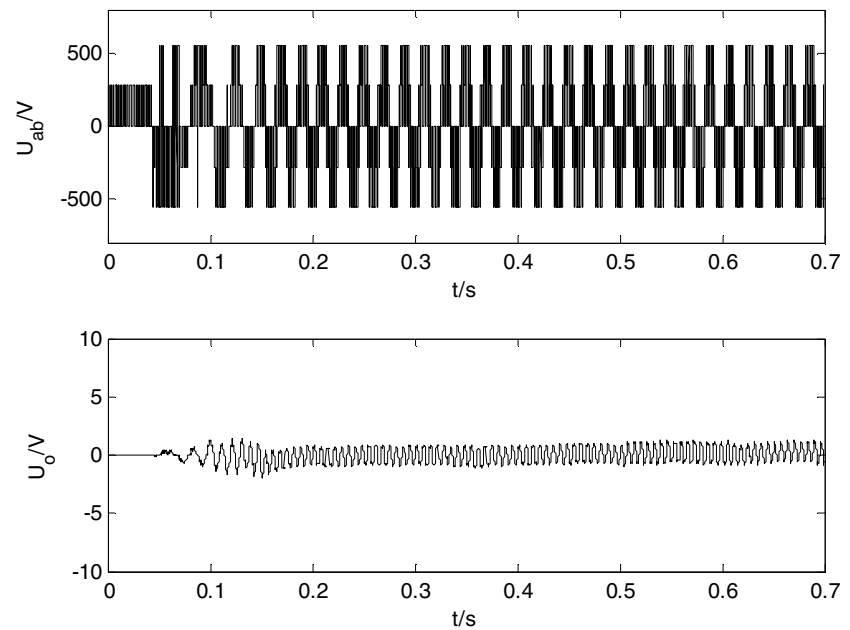

Fig. 5. Response of line voltage and fluctuation in neutral point voltage.

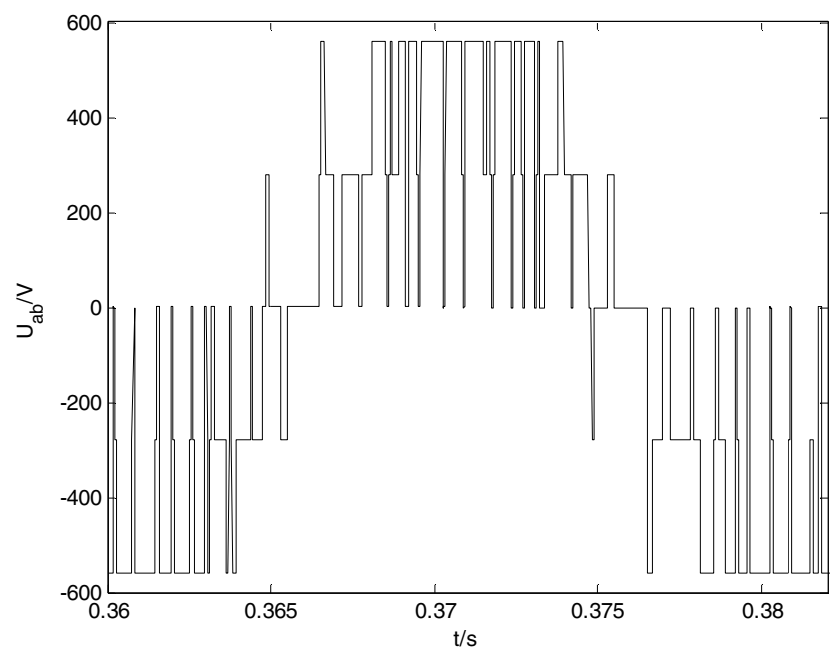

Fig. 6. Zoomed line voltage at 1500rpm

\section{B. Hardware Implementation}

An experimental prototype has been developed to implement the 3-level DTC drive. This has three parts: a 3level inverter, an induction motor and a TMS320F2812 DSPbased control board. The neutral point of the 3-level inverter is floating and controlled as discussed in Section II. The TMS320F2812 is a fixed-point 32-bit DSP which is characterized by strong computation ability; it is very suitable for the digital control of a motor drive. The IQmath library and $\mathrm{C}$ language were utilized in order to obtain high precision and fast computation. There are many of peripheral resources in the DSP, including high speed AD conversion, two event managers (EVs) and sophisticated communication interfaces, etc. These facilitated the development of the motor control. A CPLD EPM7256AE was also incorporated into the control board to implement dead time, pulse management and to generate the final 12 triggering pulses. The DSP controller has a sufficient capacity in order to carry out the intensive computations, and it only needs $3.2 \mu$ s to fulfill the computation of the speed-adaptive observer. Fig. 7 illustrates the developed sensorless drive. The main circuits for the 3level inverter, DSP control board and $2.2 \mathrm{~kW}$ motor-generator are presented in Figs. 7(a), (b) and (c), respectively. Fig. 7(d) shows the 6RA70 controller, which is used to apply external load and implement 4-quardrant operation.

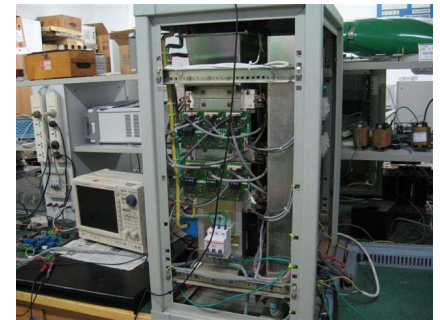

(a) 3-level inverter

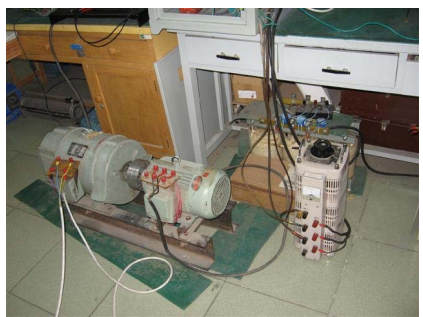

(c) $2.2 \mathrm{~kW}$ motor-generator

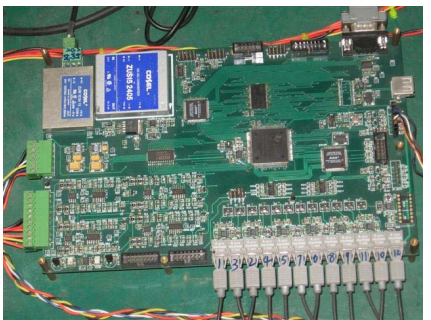

(b) DSP control board

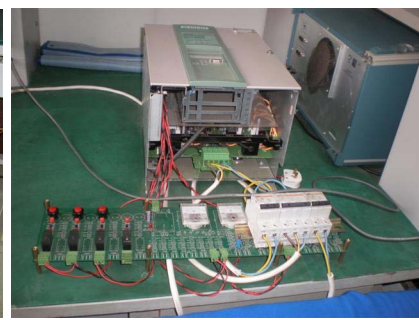

(d) 6RA70 controller
Fig. 7. Experimental setup of 3-level DTC drive.

\section{Experimental Results}

The experimental results were obtained from a 3-level inverter-fed sensorless DTC motor drive under various conditions, such as starting response, response to external disturbance, steady state response and low speed operation with or without load, etc. All internal variables such as stator flux, torque, estimated and real speed were viewed and recorded through a four-channel DA converter in DSP control board. It should be noted that the real speed was obtained from an encoder mounted on the motor - this was used only for comparison.

Figs. 8 and 9 show the starting response from $0 \mathrm{rpm}$ up to $1500 \mathrm{rpm}$ with and without pre-excitation. It is seen that if motor starts directly, there is large starting current and the peak values reach $15 \mathrm{~A}$. By first establishing stator flux, the motor can start with sufficient torque and the peak value of current is only $9 \mathrm{~A}$, which validates the effectiveness of the pre-excitation technique. 


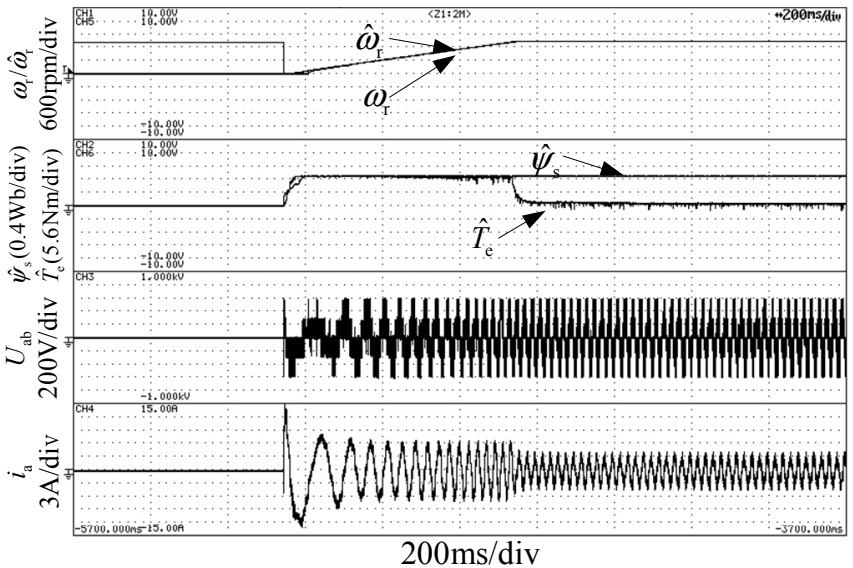

Fig. 8. Starting response without pre-excitation.

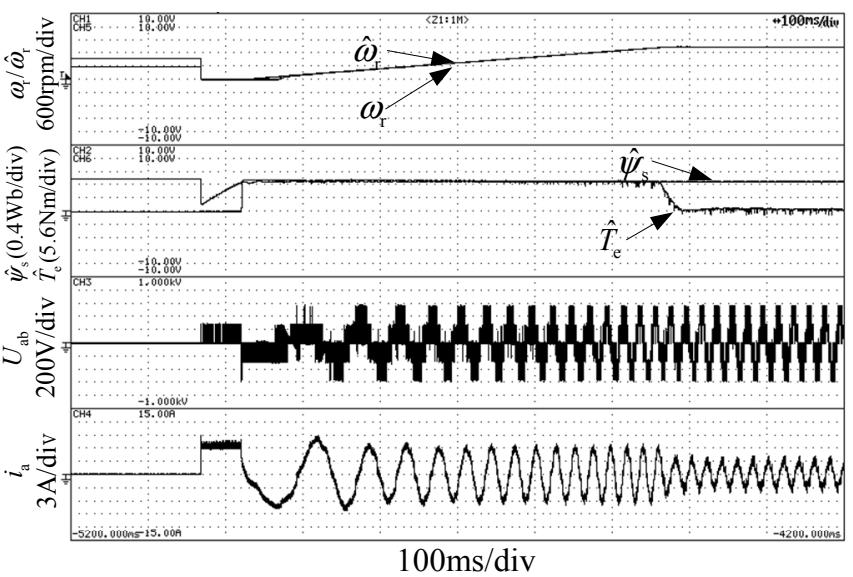

Fig. 9. Starting response with pre-excitation.

The robustness to external disturbance was tested and the results are illustrated in Fig. 10. Full-load was applied to the sensorless drive and then removed. It can be seen that there was only a slight drop in the speed response before recovery, which confirms the robustness of DTC to external disturbance.

From Fig. 11 it can be seen that there is no high voltage jump in the line voltage, which proves that the proposed optimal switching table and the principles of the vector selection are correct.

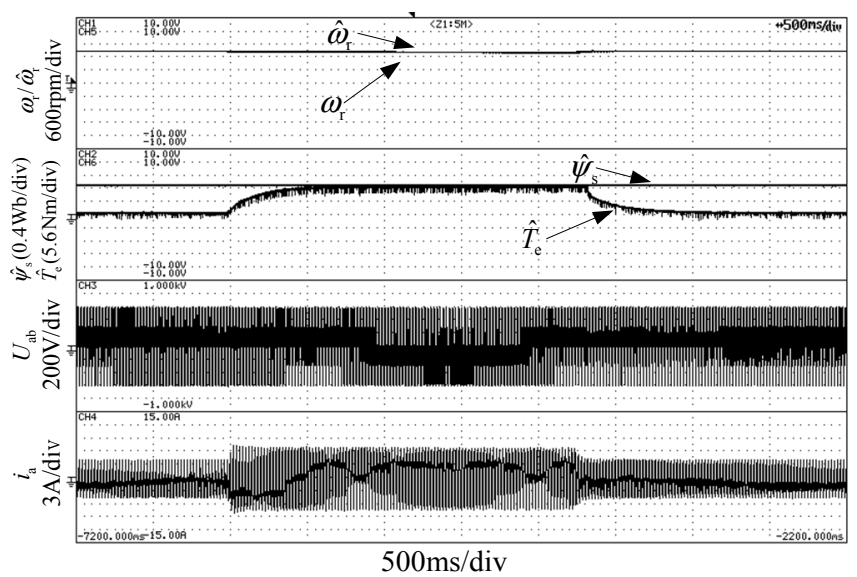

Fig. 10. Response to step load change.

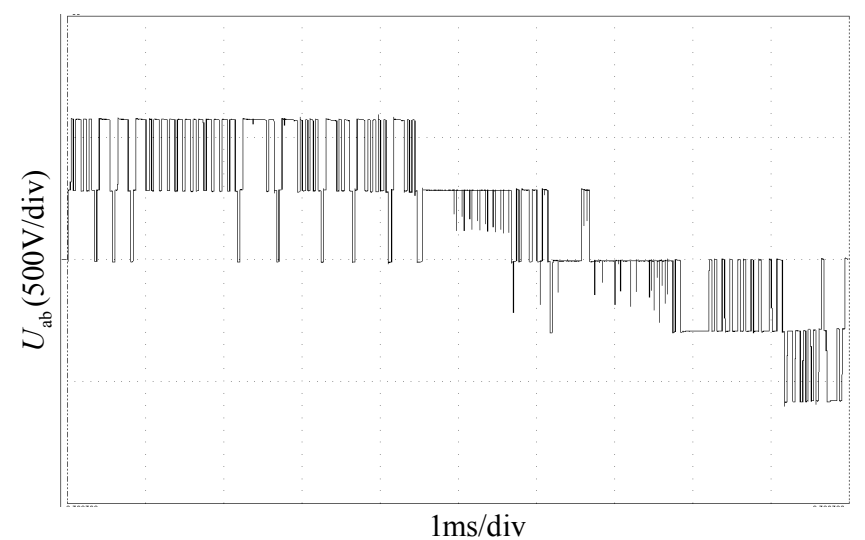

Fig. 11. Zoomed line voltage at $1500 \mathrm{rpm}$.

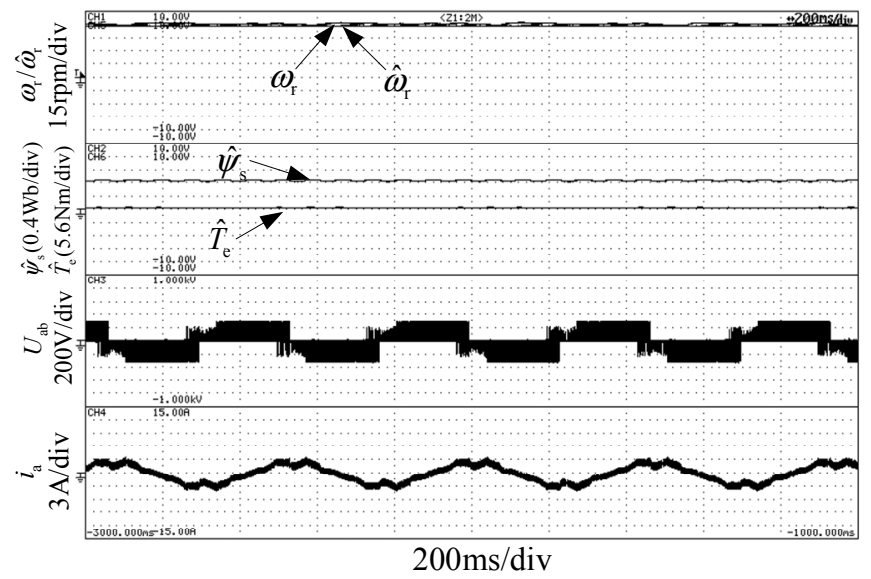

Fig. 12. Steady state response at $60 \mathrm{rpm}$ without load.

Finally, low speed operation without and with load were tested. Fig. 12 shows the steady operation at $60 \mathrm{rpm}$. It is seen that the estimated speed exactly matches the real speed. The sensorless drive can work down to $30 \mathrm{rpm}$ with full load, as illustrated in Fig. 13, which exhibits excellent performance in the low speed range.

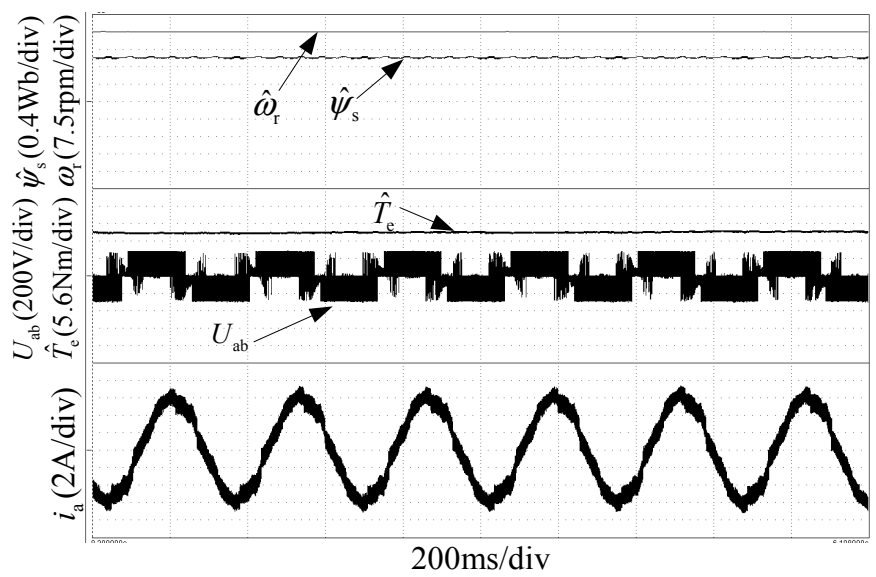

Fig. 13. Steady state response at $30 \mathrm{rpm}$ with full load. 


\section{CONCLUSION}

A sensorless 3-level inverter-fed induction motor drive is presented in this paper, which incorporates an optimal vector table and a speed-adaptive flux observer. Some aspects, including voltage jump, neutral point balance and large starting current, are investigated to assess the practicality of the 3-level DTC. The principles of the vector selection procedures are established and the pre-excitation technique is proposed to decrease the starting current. Both the presented simulation and experimental results confirm the effectiveness of the proposed schemes.

\section{REFERENCES}

[1] A. Nabae, I. Takahashi, and H.Akag, "A new neutral-point clamped PWM inverter," IEEE Trans. Ind. Applicat., vol. 17, no. 5, 1981, pp. 518-523.

[2] J. Rodriguez, J. Sh. Lai, and F. Zh. Peng, "Multilevel inverters: a survey of topologies, controls, and applications," IEEE Trans. Ind. Electron., vol. 49, no. 4, 2002, pp. 724-738.

[3] Casadei D, Profiuno F, Serra G, et al. FOC and DTC: two viable schemes for induction motors torque control. IEEE Trans. Power Electron., vol. 17, no. 5, 2002, pp. 779-787.

[4] Giusepp S. Buja, Marian P. Kazmierkowski. Direct torque control of PWM inverter-fed AC motors-a survey. IEEE Trans. Ind. Electron., vol. 51, no. 4, 2004, pp. 744-757

[5] L. Kyo-Beum, S. Joong-Ho, I. Choy, et al. Improvement of low-speed operation performance of DTC for three-level inverter-fed induction motors. IEEE Trans. Ind. Electron., vol. 48, no. 5, 2001, pp. 1006-1014

[6] Sapin A., Steimer P.K., Simond J.J. Modeling, Simulation, and Test of a Three-Level Voltage-Source Inverter with Output LC Filter and Direct Torque Control. IEEE Trans. Ind. Electron., vol. 43, no. 2, 2007 , pp. 469-475.

[7] Juhasz G, Halasz S, Veszpremi K. New aspects of a direct torque controlled induction motor drive. IEEE ICIT'00, 2000, no.1, pp. 43-48.

[8] Yongchang Zhang, Zhengming Zhao. "Speed Sensorless Control for Three-Level Inverter-Fed Induction Motors Using an Extended Luenberger Observer," in proc. IEEE Vehicle Power and Propulsion Conference, Harbin, Sept. 2008, CD-ROM. 